\title{
Selecting Egg and Sperm Donors: The Role of Age, Social Class, Ethnicity, Height and Personality
}

\author{
Adrian Furnham1, Natalie Salem', David Lester ${ }^{2}$ \\ ${ }^{1}$ Research Department of Clinical, Educational and Health Psychology, University College London, London, UK \\ ${ }^{2}$ Department of Psychology, The Richard Stockton College of New Jersey, Galloway Township, USA \\ Email: a.furnham@ucl.ac.uk
}

Received 23 December 2013; revised 24 January 2014; accepted 21 February 2014

Copyright (C) 2014 by authors and Scientific Research Publishing Inc.

This work is licensed under the Creative Commons Attribution International License (CC BY). http://creativecommons.org/licenses/by/4.0/

c) (i) Open Access

\section{Abstract}

This paper reports two studies where respondents were asked to help a friend make a decision about egg and sperm donation. In both studies they were presented with 16 hypothetical person's which they were asked to rate for suitability. In the first study on egg donation the hypothetical donors differed on age (18 - 20 years vs. 30 - 33 years), social class (I/II vs. III/IV), Ethnicity (Caucasian vs. Asian) and Personality (Extraversion vs. Introversion). Effects were strongest for age and ethnicity with a preference for younger Caucasians. In the second study $16 \mathrm{sperm}$ donors were described who differed similarly in age, social class and ethnicity, but personality was substituted for height (5'6" to 5'8" vs. 6'1" to 6'3"). There were strong main effects for social class, ethnicity and height with the respondents choosing middle class, tall, Caucasians. There were various significant interactions. Between subject factors (sex, ethnicity and religion) were also examined. Implications and limitations were considered.

\section{Keywords}

Mate Selection; Egg/Sperm Donation; Social Class

\section{Introduction}

Studies on mate criteria of heterosexual individuals have been particularly concerned with two areas, namely sex differences and similarity preferences. Buss $(1985,1987)$ noted that women are more concerned with prospective partner's potential earning ability, while men pay relatively more attention to physical factors, such as attractiveness and health. Both women and men are concerned with partners' attractiveness and resourcefulness, 
however there are significant differences in the weight given to these two sorts of characteristics.

There is now a growing literature on the topic of mate preferences and selection (Kurzban \& Weeden, 2005; Shackelford, Schmitt, \& Buss, 2005; Wood \& Brumbaugh, 2009). Studies in this area fall into various further categories such as the content analysis of "lonely hearts" columns (Harrison \& Saeed, 1977; Greenlees \& McGrew, 1994) and post speed interactions ratings (Kurzban \& Weeden, 2005). There have also been rating studies of vignettes and pictures (Wood \& Brumbaugh, 2009). In study of participants who signed up to a dating service Kurzban and Weeden (2005) found both sexes paid particular attention to observable physical attributes like age, attractiveness, BMI and height but not less observable characteristics like education, religion, sociosexuality or ideas about children. Experimental mate preference studies have also been done (Buss \& Angleitner, 1989).

More recent research has specified the role of personality factors in mate selection (Wood \& Brumbaugh, 2009). Klohnen and Luo (2005) used a couple-centered approach and looked at newlyweds' assortative mating issues. Results showed that on 19 of the 21 domains under investigation, real couples were more similar than randomly paired couples, and this provided consistent spouse similarity but none for complementarily. Furnham (2009) got young people to rate 14 desirable potential characteristics classified under five headings (ability, personality, physical, social and values). Females rated intelligence, stability, conscientiousness, height, education, social skills and political/religious compatibility significantly higher than males, who rated good looks higher than females.

The studies in this paper look at the choice of egg and sperm donors. By accepting sperm or egg donations one is making a very clear selection about genetic inheritance rather than a supportive partner or mate. There are a number of studies on egg and sperm donation (Lampic, Svanberg, \& Sydsja, 2009; Purewal \& van den Akker, 2006; Scheib, 1994; Scheib \& Ruby, 2006). Scheib (1994) reported on two experimental studies. In the first study she asked participants to rate 15 characteristics that they might look for in a donor and which grouped into four factors labelled character, health, physical and abilities. Participants rated character first, and health second, despite the belief that donor character had little likelihood of affecting the resultant child. A second study added resource potential which was rated as moderately important. It seems few others studies have used this methodology to investigate mate choice.

This paper considers the issue of mate selection from a somewhat different point of view. First, by our definition, the "mate" is simply an egg or sperm donor with whom one may have no contact and about whom there is limited information. What is known is that the sperm/eggs are healthy and that legal requirements have been met. The study focuses on how participants weight the information provided. Second, in this study participants are asked to advise a close friend on the mate choice rather than make it for themselves.

In all previous studies on this topic participants are asked to make mate choice decisions on the basis of person descriptions, photographs, brief video portrayals or even face-to-face interaction. Usually characteristics of the "stimulus figure" are systematically varied, or rated to test hypotheses. The study follows the method used in studies on the allocation of scarce medical (and other resources) (Furnham, Ariffin, \& McClelland, 2007). It also follows the study of Birenbaum-Carmeli and Carmeli (2002) who, in a questionnaire study of 212 Israeli recipients of donor insemination, examined preferences for specific (height, eye and skin colour) physiognomic features that would like their donor to have. They tested and confirmed the theory that recipients would prefer donors who had an appearance similar to that of their partner.

\section{Study 1}

The first study looked at the issue of female egg donors. Participants were given short vignettes describing donor differing on four dimensions in a $2 \times 2 \times 2 \times 2$ experimental design.

The four dimensions were age (18 - 21 vs. 30 - 33), profession (occupations in social class I vs. III), ethnicity (Caucasian vs. Asian) and personality (Introvert vs. Extravert). It was predicted that H1: Younger people would be chosen over older because of their fitness,

H2: Social Class I over III because it is a marker of intelligence and the ability to acquire resources through well paid work; H3: Caucasian over Asian to match race of donor with hypothetical recipient (and themselves); and H4: Extravert over Introverts because of the belief that extraverts are happier and more socially skilled (Furnham, 2009). No hypotheses were made about possible interactions nor individual difference correlates of preferences. 


\section{Method}

\subsection{Participants}

The participants of this study were one hundred and ninety-eight participants (155 females and 43 males), ranging in age from 18 to 62 years $(M=22.41, S D=6.26)$. Eighty five percent of participants were undergraduate or postgraduate students, and the remainder were employed. The sample consisted primarily of Caucasian participants (59.6\% Caucasian; 20.7\% Asian; 19.7\% unspecified "other") who were single (61.9\%) or in committed romantic relationships (33.5\% dating, 2\% married; $2.5 \%$ other), and childless (93.9\%; 6.1\% had 1 to 4 children). In terms of religious affiliation, most participants indicated some religious affiliation (55.1\% Christian, 5.1\% Jewish, 4.6\% Muslim, 13.3\% unspecified “other"), while others indicated no religious affiliation (16.3\%) or uncertainty regarding their beliefs (5.6\%).

\subsection{Materials}

All participants completed a two-part questionnaire comprising the "Egg Donor Suitability" questionnaire and a section of demographic questions. The construction of the questionnaire was based on techniques used in previous studies to assess patient prioritisation for the allocation of scarce medical resources (e.g., Furnham, Ariffin, \& McClelland, 2007; Furnham, Hassomal, \& McClelland, 2002; Furnham, Thomas, \& Petrides, 2002; Furnham, Thomson, \& McClelland, 2002). All participants were first asked to imagine the following:

A very close couple of yours has asked for some advice. For personal medical reasons they are only going to be able to have a family through egg donation. They have been told about the full procedure, which is both safe and successful. Through a reputed agency, the couple have been able to track down 16 women who will provide eggs and give birth to the child. They know certain details about the donor and have asked you to give advice on the choice.

Participants were then presented with a short description of 16 hypothetical egg donors, who they rated for suitability using a 9-point scale ( $0=$ Definitely No and $8=$ Definitely Yes). Each egg donor varied on the following four characteristics: age (young/old), occupation (non-professional/professional), ethnicity (European Caucasian/Asian), and personality (introverted/extraverted). Young donors were aged between 18 and 21 years, and old donors were aged 30 to 33 years. Examples of occupations used to describe non-professional donors include nurse, beautician, and chef, while examples for professional donors include lawyer, architect or accountant. Young, non-professional donors were described as apprentice nurses, beauticians, or chefs, and young, professional donors were described as pursuing university careers in Law, Architecture or Accountancy to ensure credibility of the descriptions.

Each donor was one particular example of the 16 possible combinations of the four characteristics. For example, a young, non-professional, Asian, extraverted egg donor was described as "Female A, aged 21, is a bubbly, extraverted Asian female who recently gained a catering qualification”. All participants were required to make their decisions based solely on this information.

In the second part of the questionnaire, participants reported their demographic information, which included age, ethnicity, marital status, number of children, current occupation, and religious affiliation.

\subsection{Procedure}

Ethical permission was first sought and obtained. Participants were recruited opportunistically from their place of work or study. Responses to the questionnaire were not time constrained and participants were permitted to return them at a later date. All participants were instructed to complete the questionnaire individually and anonymously. Following completion of the study, were possible participants were fully debriefed. The response rate was over $90 \%$.

\subsection{Initial Data Processing}

Preliminary analyses indicated that skewness was high and negative for 13 of the 16 description ratings (skewness range $=-0.386$ to -1.56 ) and that kurtosis was high for 2 of the 16 ratings (kurtosis $=1.687$ and 3.228). Therefore, to ensure that the assumptions of the ANOVA were met, all ratings were transformed to approximate 
normality using the Box-Cox power transformation procedure (Box \& Cox, 1964).

\section{Results}

\subsection{Egg Donor Characteristics}

A $2 \times 2 \times 2 \times 2$ repeated measures ANOVA was conducted with the four egg donor characteristics (age, occupation, ethnicity, and personality) as the within-subjects variables. Table 1 shows mean ratings, F-ratios, and partial eta-square values. All main effects were significant, confirming all four hypotheses. Professional women (M $=5.41, \mathrm{SE}=.08)$ were preferred as donors to non-professional women $(\mathrm{M}=4.70, \mathrm{SE}=.08 ; \mathrm{F}(1,197)=103.41$, $p<.05, \eta 2 p=.34)$, extraverted women $(\mathrm{M}=5.35, \mathrm{SE}=.08)$ were preferred to introverted women $(\mathrm{M}=4.75$, SE $=.09 ; \mathrm{F}(1,197)=68.07, p<.05, \eta 2 \mathrm{p}=.26)$, European Caucasian women $(\mathrm{M}=5.27, \mathrm{SE}=.07)$ were preferred to Asian women $(\mathrm{M}=4.84, \mathrm{SE}=.09 ; \mathrm{F}(1,197)=52.17, p<.05, \eta 2 \mathrm{p}=.21)$, and younger women $(\mathrm{M}=5.16$, SE $=.09)$ were preferred to older women $(\mathrm{M}=4.94, \mathrm{SE}=.09 ; \mathrm{F}(1,197)=52.17, p<.05, \eta 2 \mathrm{p}=.21)$. Partial eta-square values showed that egg donor occupation was the most important factor and age the least important factor in participants' ratings.

There were five two-way and two three-way interactions. The two-way interactions between occupation and personality $(\mathrm{F}(1,197)=99.16, p<.05, \eta 2 \mathrm{p}=.34)$, occupation and age $(\mathrm{F}(1,197)=73.17, p<.05, \eta 2 \mathrm{p}=.27)$, and occupation and ethnicity $(\mathrm{F}(1,197)=14.65, p<.05, \eta 2 \mathrm{p}=.07)$ indicating that participants generally preferred professional egg donors, but that this preference was stronger for extraverted donors $(F(1,197)=173.31$, $p<.05, \eta 2 p=.47)$ than for introverted donors $(F(1,197)=12.76, p<.05, \eta 2 p=.06)$, for older donors $(F(1,197)=$ $164.75, p<.05, \eta 2 \mathrm{p}=.46)$ than for younger donors $(\mathrm{F}(1,197)=15.65, p<.05, \eta 2 \mathrm{p}=.07)$, and for European Caucasian donors $(\mathrm{F}(1,197)=117.18, p<.05, \eta 2 \mathrm{p}=.37)$ than for Asian donors $(\mathrm{F}(1,197)=31.77, p<.05, \eta 2 \mathrm{p}$ $=.14)$. The two-way interactions between age and ethnicity $(\mathrm{F}(1,197)=12.99, p<.05, \eta 2 p=.06)$ and age and personality $(\mathrm{F}(1,197)=9.06, p<.05, \eta 2 \mathrm{p}=.04)$ showed that young European Caucasians and young extraverts were more likely to be chosen as donors than old European Caucasians $(\mathrm{F}(1,197)=12.63, p<.05, \eta 2 \mathrm{p}=.06)$ and old extraverts $(\mathrm{F}(1,197)=10.81, p<.05, \eta 2 \mathrm{p}=.05)$, respectively.

The three-way interactions between occupation, personality, and age $(\mathrm{F}(1,197)=27.96, p<.05, \eta 2 \mathrm{p}=.12)$ showed that professional donors were rated as more suitable than non-professional donors, however, this preference was stronger for old extraverts than for old introverts. The second three-way interaction between occupa-

\begin{tabular}{|c|c|c|c|}
\hline & Mean rating (SE)+ & $F(1,197)$ & Partial $\eta 2$ \\
\hline Occupation & & $103.41^{* *}$ & .34 \\
\hline Professional & $5.41(.08)$ & & \\
\hline Non-professional & $4.70(.08)$ & & \\
\hline Personality & & $68.07^{* *}$ & .26 \\
\hline Introvert & $4.75(.09)$ & & \\
\hline Extravert & $5.35(.08)$ & & \\
\hline Ethnicity & & $52.17^{* *}$ & .21 \\
\hline European/Cauc & $5.27(.07)$ & & \\
\hline Asian & $4.84(.09)$ & & \\
\hline Age & & $5.89^{*}$ & .03 \\
\hline Younger & $5.16(.09)$ & & \\
\hline Older & $4.94(.09)$ & & \\
\hline
\end{tabular}

+Scale: 0 = Definitely NO - 8 Definitely YES ${ }^{*} p<.05,{ }^{* *} p<.001$. 
tion, personality, and ethnicity $(\mathrm{F}(1,197)=12.20, p<.05, \eta 2 \mathrm{p}=.06)$ resulted from the attenuation of the occupation x personality interaction for Caucasian donors $(\mathrm{F}(1,197)=80.68, p<.05, \eta 2 p=.29)$ compared to Asian donors $(\mathrm{F}(1,197)=21.64, p<.05, \eta 2 p=.10)$. Finally, there was a four-way interaction between occupation, personality, age, and ethnicity $(\mathrm{F}(1,197)=5.07, p<.05, \eta 2 \mathrm{p}=.03)$. This was due to the absence of the age $\mathrm{x}$ ethnicity x occupation interaction for Asian donors $(\mathrm{F}(1,197)=3.64, p>.05, \eta 2 \mathrm{p}=.02)$.

\subsection{Participant Demographics}

To explore possible interactions between participant and egg donor demographics, the above analysis was repeated, entering participant ethnicity, relationship status, and gender, separately, as between-subjects factors. With regards to participant ethnicity, results showed that there were three interactions with donor demographics. There was a significant two-way interaction between age and participant ethnicity $(\mathrm{F}(1,156)=14.67, p<.05$, $\eta 2 \mathrm{p}=.09)$, indicating that preferences for younger donors were stronger in Caucasian $(\mathrm{F}(1,117)=19.45, p<.05$, $\eta 2 \mathrm{p}=.14)$ than in Asian participants $(\mathrm{F}(1,117)=4.38, p<.05, \eta 2 \mathrm{p}=.10)$. The two-way interaction between egg donor ethnicity and participant ethnicity $(\mathrm{F}(1,156)=11.49, p<.05, \eta 2 \mathrm{p}=.07)$ showed that European Caucasian participants preferred Caucasian to Asian donors $(\mathrm{F}(1,117)=48.39, p<.05, \eta 2 p=.29)$. Asian participants showed no differences in their preferences for donor ethnicity $(\mathrm{F}(1,117)=3.92, p>.05, \eta 2 \mathrm{p}=.03)$. The three-way interaction between age, donor ethnicity, and participant ethnicity $(F(1,156)=4.30, p<.05, \eta 2 p$ $=.03$ ) indicated that European Caucasian participants preferred younger donors to older donors, but that this preference was stronger for Caucasian donors than for Asian donors $(\mathrm{F}(1,117)=19.14, p<.05, \eta 2 \mathrm{p}=.03)$. Again, Asian participants showed no differences in their preferences $(\mathrm{F}<1)$.

There were two interactions involving participants' relationship status. Firstly, there was a two-way interaction between age and relationship status $(\mathrm{F}(1,190)=7.79, p<.05, \eta 2 \mathrm{p}=.04)$, showing that participants who were in a relationship preferred younger donors to older donors $(\mathrm{F}(1,190)=18.32, p<.05, \eta 2 p=.13)$. There was no difference in preferences among those who were not in a relationship $(F<1)$. Secondly, there was a significant three-way interaction between occupation, personality, and relationship status $(\mathrm{F}(1,190)=4.61, p<.05$, $\eta 2 \mathrm{p}=.02$ ). This was due to the attenuation of the occupation $\mathrm{x}$ personality interaction in participants who were not in a relationship $(\mathrm{F}(1,123)=40.54, p<.05, \eta 2 \mathrm{p}=.25)$ in comparison to those participants who were in a relationship $(\mathrm{F}(1,67)=58.82, p<.05, \eta 2 \mathrm{p}=.47)$. There was only one interaction involving participant gender. This was a three-way interaction between occupation, personality, and gender $(\mathrm{F}(1,196)=7.20, p<.05, \eta 2 \mathrm{p}$ $=.04)$, which was due to the absence of an occupation $\mathrm{x}$ personality interaction among male participants $(\mathrm{F}(1,42)$ $=3.83, p>.05, \eta 2 p=.08)$.

\section{Study 2}

Study 2 was a part replication and part extension of study 1 . First, while the first study concerned selecting female egg donors, the second study looked at male sperm donors.

Second, the personality factor was replaced by height. Also the occupations described to indicate social class were changed to make them more appropriate for males. Three of the four hypotheses were the same with respect to age, social class and ethnicity while the fourth hypothesis was that taller rather than shorter male donors would be selected. Again, no hypotheses were entertained about interactions or individual difference correlates of the ratings.

\section{Method}

\subsection{Participants}

Three hundred and eighteen participants (268 female and 50 male) took part in the study, whose ages ranged from 18 to 62 years $(\mathrm{M}=22.42, \mathrm{SD}=6.69)$. The majority of participants were undergraduate or postgraduate students (92.6\%), while the remainder were in employment (7.4\%). In terms of ethnicity, 61.0\% were of European Caucasian descent, 24.7\% were of Asian descent, and 14.3\% unspecified "other". Over half of the total sample was single (56.0\%), while most others were in a relationship (34.2\% dating, $7.2 \%$ married). In all, $91.0 \%$ of participants were child-free and the rest had between 1 to three children. When asked about religion, $46.5 \%$ of the sample indicated Christian beliefs, 8.9\% indicated Muslim beliefs, $4.8 \%$ indicated Jewish beliefs, and 17.8\% unspecified "other". 


\subsection{Questionnaire}

All participants received a 2-page questionnaire. The questionnaire described a hypothetical close friend who, for personal medical reasons, was only going to be able to conceive and become pregnant through sperm donation. Participants were told that their friend had been provided with several descriptions of potential sperm donors and that they had been asked to assist their friend in rating the desirability of each sperm donor.

The sperm donors differed on four demographics: age (young/old), occupation (non-professional/professional), ethnicity (European Caucasian/Asian), and height (short/tall). Young donors ranged in age from 18 to 21 years, and old donors ranged from 30 to 33 years. Donors from a non-professional background were described as electricians, plumbers, or mechanics, whereas donors from a professional background were described as lawyers, architects, or accountants. To ensure credibility of the descriptions, young, non-professional donors were described as apprentice electricians, plumbers, or mechanics, and young, professional donors were described as pursuing university careers in Law, Architecture or Accountancy. Finally, short donors ranged in height from 5 '6" to 5'8" and tall donors ranged from 6'1" to 6'3".

There were 16 possible combinations of sperm donor demographics and all participants rated all 16 descriptions using a 9-point scale $(0=$ Definitely No and $8=$ Definitely Yes $)$. Participants were told that the sperm of each donor were equivalent in their quality and quantity to ensure that they were only using the demographic manipulations to inform their ratings. In the final part of the questionnaire, participants were asked to provide their demographic details, including age, ethnicity, marital status, number of children, current occupation, and religion.

\subsection{Procedure}

As before ethics permission was sought and obtained. Participants represented a convenience sample recruited from a number of universities and workplaces. All participants completed the questionnaires individually and in their own time, and were not remunerated for their participation. There was an $85 \%$ response rate. In total, the questionnaire took approximately 15 minutes to complete, and where possible all participants were fully debriefed upon completion of the questionnaire.

\subsection{Initial Data Processing}

Fourteen of the 16 sperm donor ratings showed a marked departure from normality; 12 of the ratings were negatively skewed (range $=-0.307$ to -1.324 ) and kurtosis was high for 8 of the ratings (range $=-0.559$ to -2.121 ). Data were therefore transformed using the Box-Cox procedure (Box \& Cox, 1964) in order to optimise distribution normality. All statistical analyses were performed on the transformed data.

\section{Results}

\subsection{Sperm Donor Characteristics}

A four-way repeated measures ANOVA was performed with the four sperm donor demographics (age, occupation, ethnicity, and height) as the within-subjects factors. Results of the ANOVA are summarised in Table 2, together with mean ratings and effect sizes (partial $\eta 2)$. All main effects, with the exception of age $(F<1)$, were significant. Three of the four hypotheses were confirmed. Professional donors $(M=5.71$, SE $=.07)$ were preferred to non-professional donors $(\mathrm{M}=4.36$, $\mathrm{SE}=.08$; $\mathrm{F}(1,317)=561.01, p<.05, \eta 2 p=.64)$, European Caucasian donors $(\mathrm{M}=5.43, \mathrm{SE}=.06)$ were preferred to Asian donors $(\mathrm{M}=4.65, \mathrm{SE}=.09 ; \mathrm{F}(1,317)=156.06, p$ $<.05, \eta 2 \mathrm{p}=.33)$, and taller donors $(\mathrm{M}=5.32, \mathrm{SE}=.07)$ were preferred to shorter donors $(\mathrm{M}=4.76, \mathrm{SE}=.08$; $\mathrm{F}(1,317)=124.78, p<.05, \eta 2 p=.28)$. In terms of the relative importance of the three significant factors, results showed that occupation was the most salient factor in sperm donor selection, while height was the least.

There were four two-way and three three-way interactions. The interactions between occupation and age $(\mathrm{F}(1$, $317)=138.14, p<.05, \eta 2 p=.30)$, occupation and ethnicity $(\mathrm{F}(1,317)=42.10, p<.05, \eta 2 p=.12)$, and occupation and height $(\mathrm{F}(1,317)=38.74, p<.05, \eta 2 \mathrm{p}=.11)$ indicated that although professionals were preferred to non-professionals, this preference was more pronounced for older donors $(\mathrm{F}(1,317)=602.42, p<.05, \eta 2 \mathrm{p}=.66)$ than for younger donors $(\mathrm{F}(1,317)=249.59, p<.05, \eta 2 \mathrm{p}=.44)$, for European Caucasians $(\mathrm{F}(1,317)=524.01$, $p<.05, \eta 2 p=.62)$ than for Asians $(\mathrm{F}(1,317)=147.12, p<.05, \eta 2 \mathrm{p}=.32)$, and for taller donors $(\mathrm{F}(1,317)=$ 484.06, $p<.05, \eta 2 \mathrm{p}=.60)$ than for shorter donors $(\mathrm{F}(1,317)=321.97, p<.05, \eta 2 \mathrm{p}=.50)$. There was also a 
Table 2. Mean ratings, F-ratios, and partial eta-square values for egg donor characteristics.

\begin{tabular}{cccc}
\hline & Mean rating (SE)+ & $\mathrm{F}(1,317)$ & Partial $\eta 2$ \\
\hline Occupation & & $561.01^{* *}$ & .64 \\
Professional & $5.71(.07)$ & & \\
Non-professional & $4.36(.08)$ & & .28 \\
Height & & $124.78^{* *}$ & \\
Short & $4.76(.08)$ & & \\
Tall & $5.32(.07)$ & & \\
Ethnicity & & \\
European/Cauc & $5.43(.06)$ & \\
Asian & $4.65(.09)$ & \\
Age & & $0.156 .06^{* *}$ & \\
Younger & $5.02(.08)$ & \\
Older & $5.05(.07)$ & \\
\hline
\end{tabular}

+Scale: 0 = Definitely NO - 8 Definitely YES ${ }^{*} p<.05,{ }^{* *} p<.001$.

significant interaction between height and ethnicity $(\mathrm{F}(1,317)=6.71, p<.05, \eta 2 \mathrm{p}=.02)$, which showed that, overall, participants preferred taller donors to shorter donors, but that this preference was stronger for donors of European Caucasian descent $(\mathrm{F}(1,317)=103.51, p<.05, \eta 2 \mathrm{p}=.25)$ than for donors of Asian descent $(\mathrm{F}(1,317)$ $=82.42, p<.05, \eta 2 p=.21)$.

The three-way interaction between occupation, age, and ethnicity $(\mathrm{F}(1,317)=11.30, p<.05, \eta 2 p=.03)$ showed that professional sperm donors were preferred to non-professional sperm donors, but that this preference was stronger for old Asians than young Asians. Finally, the three-way interactions between height, occupation, and ethnicity $(\mathrm{F}(1,317)=14.72, p<.05, \eta 2 \mathrm{p}=.04)$ and height, occupation, and age $(\mathrm{F}(1,317)=11.47, \mathrm{p}<.05$, $\eta 2 p=.04)$ indicated that tall donors were consistently preferred to short donors. However, this effect was stronger for Caucasian professionals than for Asian professionals, and stronger for young non-professionals than for old non-professionals.

\subsection{Participant Demographics}

Following this analysis, participant ethnicity, relationship status, and gender were examined as between-subjects variables. With regards to participant ethnicity, results showed that there was a significant two-way interaction between age and participant ethnicity $\left(F_{(1,156)}=3.92, p<.05, \eta^{2} p=.03\right)$, For participant ethnicity, results showed that there were three interactions with donor demographics. There was a two-way interaction between donor ethnicity and participant ethnicity $\left(F_{(1,253)}=22.22, p<.05, \eta^{2} p=.08\right)$, which indicated that preferences for Caucasian donors over Asian donors were more pronounced for Caucasian $\left(F_{(1,180)}=162.88, p<.05, \eta^{2} p\right.$ $=.48)$ than for Asian participants $\left(F_{(1,73)}=15.06, p<.05, \eta^{2} p=.17\right)$. There was a three-way interaction between occupation, height, and participant ethnicity $\left(F_{(1,253)}=8.50, p<.05, \eta^{2} p=.03\right)$, which reflected stronger preferences among Asian, compared to Caucasian, participants for tall professional donors compared to short professional donors. The third interaction was between occupation, age, donor ethnicity, and participant ethnicity $\left(F_{(1,}\right.$ 296) $=8.38, p<.05, \eta^{2} p=.03$ ). This was due to the absence of an occupation $\mathrm{x}$ age $\mathrm{x}$ donor interaction among Caucasian participants $(F<1)$.

Results for participant relationship status indicated a two-way interaction between height and relationship status $\left(F_{(1,296)}=4.40, p<.05, \eta^{2} p=.02\right)$, which showed that preferences for tall donors were stronger in participants who were not in a relationship $\left(F_{(1,171)}=94.53, p<.05, \eta^{2} p=.36\right)$ than participants who were in a relationship $\left(F_{(1,125)}=27.06, p<.05, \eta^{2} p=.18\right)$. There was also a two-way interaction between ethnicity and relationship status $\left(F_{(1,317)}=14.72, p<.05, \eta^{2} p=.04\right)$ showing that preferences for Caucasian donors were stronger 
in participants who were in relationships $\left(F_{(1,125)}=85.32, p<.05, \eta^{2} p=.41\right)$ than those who were not in relationships $\left(F_{(1,171)}=73.44, p<.05, \eta^{2} p=.30\right)$. Finally, there was a three-way interaction between occupation, height, and relationship status $\left(F_{(1,296)}=6.28, p<.05, \eta^{2} p=.02\right)$. This reflected the stronger preference of participants who were not in a relationship for tall professional versus short professional donors.

There were two interactions involving participant gender. The first was a four-way interaction between height, occupation, age, and gender $\left(F_{(1,316)}=4.78, p<.05, \eta^{2} p=.02\right)$. This was due to the absence of a height $\mathrm{x}$ occupation $\mathrm{x}$ age among male participants $(F<1)$. The second was a four-way interaction between height, ethnicity, age, and gender $\left(F_{(1,316)}=5.34, p<.05, \eta^{2} p=.02\right)$, which was due to the absence of a corresponding height $\mathrm{x}$ ethnicity $\mathrm{x}$ age interaction among female participants $(F<1)$.

\section{Discussion}

The results of both studies showed that it was the occupation of the donor (both sperm and egg) that was the factor that participants most differentiated between people. There was a strong preference for donors coming from recognised professions rather than skilled workers. Profession could be seen as a proxy for intelligence, which lay people see both as heritable and a marker of economic success and therefore resource acquisition (Furnham, 1988). Previous studies have shown that women favour intelligent men because it is seen as a cue for provisioning abilities (Prokosch, Coss, Scheib, \& Bozis, 2009). This study provided additional evidence for this hypothesis but showed that the same was true for selecting female mates. Profession might also be an indicator of other characteristics to observers like education, educability and conscientiousness as well as specific abilities. Certainly it is used widely in situations where people describe themselves and "advertise" for a mate (Furnham, 2009).

The role of age was least important in both studies and non significant in the second. Participants marginally preferred a younger female egg donor over an older donor but did not differentiate between the male sperm donors. There are probably two reasons for this effect. First, the age ranges in this study may not have been enough to show a large effect. Thus if the older group were described as 40 - 43 years rather than 30 - 33 years, the results may have been stronger. Also people know that male sperm count and motility declines with age. Second, it is known that whereas women have a limited time to produce eggs and that younger women are probably healthier than older women; the same is not the same for men whose sperm count and quality decrease at a much slower rate.

Both studies showed a preference for Caucasian/European donors over Asian donors. This is particularly interesting as the race of the receiver of the eggs/sperm was not specified. In both studies there were about one two third Europeans and one fifth Asians. It may be assumed that the participants may have assumed that their friend(s) were of the same race as them and hence it was possible to investigate a participant ethnicity $\mathrm{x}$ donor ethnicity interaction. Both studies showed very similar results which did indeed indicate a preference for a donor of one's own race group but that that preference was much stronger among the (dominant) white Caucasian/European origin population. No doubt if a similar race couple were to accept egg/sperm from a person of a different race it would be much more apparent that the child was the result of donation which may be an important issue for parents.

The first study showed that extraverts were preferred over introverts. It is unclear the extent to which people believe that this characteristic is heritable but there are indications that lay people believe extraverts much more socially adapted, healthy and happy than introverts (Furnham, 2008). Indeed the participants seemed more concerned with the participants' personality as with their race, which was also found by Scheib (1994).

The second study showed that participants preferred the sperm of taller vs. shorter than average men. This confirms the study, similar to this, by Birenbaum-Carmeli and Carmeli (2002). There is indeed evidence in the evolutionary psychology literature which shows the particular benefits of height in men (Swami \& Furnham, 2008). What seems most important is the relative height in couples when it is preferable that the male is taller than the female. This gives taller men an advantage because they presumably have a greater choice of females. In this study the shorter men were marginally shorter than the average and it could be, as with the age variable, that the wider the difference between the heights of the two groups the more powerful this variable would difference the preferences of the participants.

This study used rather different methodology to explore the mate choice issue in evolutionary psychology. Previous findings were confirmed: a preference for taller men with jobs that commanded higher salaries; and for 
people of one's own racial group. This study also implications for studies of beliefs about the genetic inheritance of specific characteristics like height and personality. Given that the strongest donor discriminator in both studies was the occupation/social class of the donor it seems worthwhile exploring what people think that this signals and how the characteristics associated with it are "passed on" to further generations.

Studies based on this methodology have obvious limitations. Participants are not making decisions for themselves but others (a close friend) who, it is assumed, are like them. Some respondents said that they did not like making decisions such as these for other people but they were informed they were to imagine that their friend has "turned to them for advice". Next, the information presented to each participant is minimal and confined to just four variables. Whilst the participants were told that the donors were healthy and had passed through the all the relevant tests and procedures, it is quite possible that there is other information they might have preferentially sought from a donor. Finally most of the participants were young, well educated people and not sufficiently representative of the population. Indeed this may in part explain the preference for the social class variable in both studies.

\section{References}

Birenbaum-Carmeli, D., \& Carmeli, Y. (2002). Psysiognomy, Familism and Consumerism: Preferences among Jewish-Israeli Recipients of Donor Insemination. Social Science and Medicine, 54, 363-376. http://dx.doi.org/10.1016/S0277-9536(01)00035-1

Box, G. E. P. \& Cox, D. R. (1964). An Analysis of Transformation. Journal of the Royal Statistical Society: Series B, 26, 211-243.

Buss, D. M. (1985). Human Mate Selection. American Scientist, 73, 47-51.

Buss, D. M. (1987). Sex Differences in Human Mate Selection Criteria: An Evolutionary Perspective. In Sociobiology and Psychology: Issues, Ideas and Application (Edited by Crawford C., Smith M. and Krebs D.). Hillsdale, NJ: Erlbaum.

Buss, D. M. \& Angleitner, A. (1989). Mate Selection Preferences in Germany and the United States. Personality and Individual Differences, 10, 1269-1280. http://dx.doi.org/10.1016/0191-8869(89)90239-0

Furnham, A. (1988). Lay Theories. Oxford: Pergamon.

Furnham, A. (2009). Sex Differences in Mate Selection Preferences. Personality and Individual Differences, 47, $622-627$. http://dx.doi.org/10.1016/i.paid.2009.03.013

Furnham, A., Ariffin, A., \& McClelland, A. (2007). Factors Affecting Allocation of Scarce Medical Resources across LifeThreatening Medical Conditions. Journal of Applied Social Psychology, 37, 2903-2921. http://dx.doi.org/10.1111/j.1559-1816.2007.00287.x

Furnham, A. F., Hassomal, A., \& McClelland, A. (2002). A Cross-Cultural Investigation of the Factors and Biases Involved in the Allocation of Scarce Medical Resources. Journal of Health Psychology, 7, 381-391. http://dx.doi.org/10.1177/1359105302007004327

Furnham, A., Thomas, C., \& Petrides, K. V. (2002). Patient Characteristics and the Allocation of Scarce Medical Resources. Psychology, Health, and Medicine, 7, 99-106. http://dx.doi.org/10.1080/13548500120101595

Furnham, A., Thomson, K., \& McClelland, A. (2002). The Allocation of Scarce Medical Resources across Medical Conditions. Psychology and Psychotherapy: Theory, Research and Practice, 75, 189-203. http://dx.doi.org/10.1348/147608302169643

Greenlees, I. A., \& McGrew, W. C. (1994). Sex and Age Differences in Preferences and Tactics of Mate Attraction: Analysis of Published Advertisements. Ethology and Sociobiology, 15, 59-72. http://dx.doi.org/10.1016/0162-3095(94)90017-5

Harrison, A. A., \& Saeed, L. (1977) Let’s Make a Deal: An Analysis of Relevations and Stipulations in Lonely Hearts Advertisements. Journal of Personality and Social Psychology, 35, 257-264. http://dx.doi.org/10.1037/0022-3514.35.4.257

Kurzban, R., \& Weeden, J. (2005) Hurrydate: Mate Preferences in Action. Evolution and Human Behavior, 26, $227-244$. http://dx.doi.org/10.1016/j.evolhumbehav.2004.08.012

Lampic, C., Svanberg, A., \& Sydsjo, G. (2009). Attitudes towards Gamete Donation among IVF Doctors in the Nordic Countries. Journal of Assisted Reproductive Genetics, 26, 231-238 http://dx.doi.org/10.1007/s10815-009-9311-0

Prokosch, M., Coss, R., Scheib, J., \& Blozis, S. (2009). Intelligence and Mate Choice. Evolution and Human Behaviour, 30, 11-20. http://dx.doi.org/10.1016/j.evolhumbehav.2008.07.004

Purewal, S., \& van den Akker, O. (2006). British Women's Attitudes towards Acolyte Donation. Patient Education and Counselling, 64, 43-49. http://dx.doi.org/10.1016/j.pec.2005.11.007 
Scheib, J. (1994). Sperm Donor Selection and the Psychology of Female Mate Choice. Ethology and Sociobiology, 15, 113-129. http://dx.doi.org/10.1016/0162-3095(94)90035-3

Scheib, J., \& Ruby, A. (2006). Impact of Sperm Donor Information on Parents and Children. Sexuality, Reproduction and Menopause, 4, 17-19. http://dx.doi.org/10.1016/j.sram.2006.03.005

Shackelford, T., Schmitt, D., \& Buss, D. (2005). Universal Dimensions of Human Mate Preferences. Personality and Individual Differences, 39, 447-458. http://dx.doi.org/10.1016/j.paid.2005.01.023

Swami, V., \& Furnham, A. (2008). The Psychology of Physical Attractiveness. Hove: Psychology Press.

Wood, D., \& Brumbaugh, C. (2009). Using Revealed Mare Preferences to Evaluate Market Force and Differential Preference Explanations for Mate Selection. Journal of Personality and Social Psychology, 96, 1226-1244.

http://dx.doi.org/10.1037/a0015300 